\title{
A problematização da violência como experiência de ensinar em Saúde*
}

Heloniza O.G. Costa ${ }^{1}$

COSTA, H. O. G. The problematics of violence as a teaching experience in the healthcare field, Interface

Comunicação, Saúde, Educação, v.3 , n.5, 1999.

This article contains a report on facing violence, which constitutes a major health care problem for the population that is within the sphere of action of the UNI-Ba Project for the Barra Sanitation District in Rio Vermelho. This issue has become fundamental as an element of the thinking involved in the development of healthcare practices as part of the process of professional training. The text debates the need for professional education to be socially contextualized, so as to provide professionals with the tools they require to face problems and the population's true health care requirements. It also comments on the strategies used to ensure a close interconnection of the world of teaching and the world of work - the reality - taking the latter as an element of fundamental importance, if active methods capable of providing a positive contribution to the development of socially committed individuals are to be adopted in the processes of teaching and learning.

KEY WORDS: violence; teaching-learning process.

O artigo traz o relato do enfrentamento da violência, enquanto problema prioritário de saúde da população da área de atuação do Projeto UNI-Bahia - Distrito Sanitário Barra - Rio Vermelho. Esta questão tornou-se fundamental para pensar o desenvolvimento de práticas de saúde no processo de formação profissional. Discute a necessidade de uma formação socialmente contextualizada, que instrumentalize os profissionais para o enfrentamento de problemas $e$ das reais necessidades de saúde da população. Comenta sobre as estratégias utilizadas para assegurar uma articulação estreita entre o mundo do ensino e o mundo do trabalho - a realidade -, considerando-a como de fundamental importância quando se pretende adotar metodologias ativas no processo ensino/aprendizagem que contribuam para a formação de sujeitos socialmente comprometidos.

PALAVRAS-CHAVE: violência; processo ensino-aprendizagem.

\footnotetext{
*Agradeço a todos os alunos, professores, representantes das organizações comunitárias, profissionais e técnicos dos serviços de Saúde e das instituições envolvidas no Fórum Comunitário de Combate à Violência, que estão dando concretude às ações. Agradeço, em especial, ao professor Jairnilson Paim, o verdadeiro autor da experiência. A mim coube, como coordenadora das atividades, elaborar a primeira versão do texto, que contou com suas contribuições, críticas e sugestões. E às companheiras Maria Eunice X. Kalil (Bice) e Ana Luiza Vilasboas, co-autoras, pois participaram nas discussões do conteúdo do trabalho, na organização e formato do texto.

${ }^{1}$ Professora da Escola de Enfermagem da Universidade Federal da Bahia; diretora executiva do Projeto UNI-Bahia.
} 
O campo da saúde tem passado por sucessivos movimentos de recomposição das práticas sanitárias, decorrentes das distintas articulações entre sociedade e Estado, definindo, em cada conjuntura, as respostas sociais às necessidades e aos problemas de saúde: a higiene, do século XVIII; a Medicina Social e o Sanitarismo do século XIX; no século atual, a Saúde Pública, o Preventivismo, a Saúde Comunitária, a Saúde para Todos no ano 2000; os SILOS / Distritos Sanitários/Cidades Saudáveis (Paim \& Almeida, 1998).

Esses movimentos têm influenciado o processo de formação dos profissionais de saúde, permitindo o desenvolvimento de iniciativas apoiadas por organizações internacionais, que apontam a inadequação da formação profissional, frente às necessidades sociais de saúde da população ${ }^{2}$. Estas iniciativas reconhecem a situação de crise na formação dos profissionais e propõem rever o papel do profissional e a prática em saúde, as condições da prestação dos serviços e os cenários para o processo ensino/ aprendizagem $^{3}$. (Feuerwerker, 1997).

Pereira (1997), fazendo uma revisão de estudos que analisam o contexto educacional neste final de milênio, afirma que a crise na educação e na formação profissional precisa ser analisada e compreendida a partir dos pressupostos que fundamentam o paradigma da ciência moderna. Este, nas palavras de Prigogine apud Pereira, "privilegia a ordem, a estabilidade, ao passo que em todos os níveis de observação reconhecemos agora o papel primordial das flutuações e da instabilidade” (p.52).

A autora acentua que as mudanças e transformações aceleradas estão trazendo instabilidade e incertezas não só ao redor de nós, mas em nosso interior, provocando mudanças em nossa forma de conceber e representar o mundo - exigindo rupturas com princípios e valores que nos serviam de referência. Citando Santos, diz que vivemos o final de um ciclo de hegemonia de uma certa ordem científica, de um paradigma que pressupõe uma única forma de conhecimento verdadeiro, cuja validade funda-se na objetividade do conhecimento, resultado da separação entre teoria e prática.

Para o paradigma da ciência moderna conhecer é sempre contar, quantificar, por isso, para se ter o conhecimento, torna-se necessário reduzir a complexidade da realidade, dividindo, fragmentando. Nossos currículos refletem esse paradigma. Fragmentados em disciplinas, partem do teórico para o prático: primeiro o aluno aprende conteúdos isolados para depois aplicá-los à realidade. Daí a ênfase em procedimentos apoiados na repetição e memorização de relações, muitas vezes arbitrárias para o aluno. Dentro dessa lógica, o conhecimento estrutura-se, predominantemente, como um saber acabado, descontextualizado e a-histórico - ao qual se chega por um único caminho. Concluindo, a autora diz que o ensino precisa de novos métodos para conviver com o presente e construir o futuro (Pereira, 1997).

Por outro lado, no Brasil, os diversos movimentos teórico-organizativos na saúde têm sido vividos em contexto de crise da assistência e de falência dos modelos de atenção, sucessiva e formalmente experimentados. Configura-se, pois, um quadro epidemiológico cada vez mais complexo, com a não resolução dos problemas de saúde da grande maioria da população,
${ }^{2} \mathrm{O}$ estudo divulgado em 1970, sobre as características gerais da educação médica na América Latina, coordenado por Juan Cesar Garcia em 1976; as reuniões sobre

"Princípios Básicos para - Desenvolvimento da Educação Médica na América Latina e no Caribe"; o trabalho de Jorge Andrade sobre o

"Marco conceptual de

la educación médica en la America Latina". Em

1976 , aconteceram as reuniões sobre

"Princípios Básicos para

o Desenvolvimento da

Educação Médica na

América Latina e no

Caribe", a Conferência

Mundial de Educação

Médica, de 1988 em

Edimburgh

(Feuerwerker, 1997, p.33-60).

${ }^{3}$ No Brasil, a partir da criação da Comissão de Ensino Médico, em 1971, que articulada a ABEM e outros setores relacionados ao ensino médico, elaboraram vários documentos críticos em relação ao ensino da medicina, apontando para a necessidade da diversificação dos cenários de prática, criticando a fragmentação do conhecimento $e$ a inadequação das metodologias pedagógicas. Outras iniciativas da ABEM colocam críticas na mesma direção, reconhecendo a necessidade da interrelacão entre a estrutura assistencial, a prática médica $e$ a

educação médica.

(Feuerwerker, 1997, p.48-51).

Na década de 80 preocupação da ABEM deslocou-se da questão dos currículos para uma formação que viabilizasse a Reforma Sanitária - realização do Seminário para

Preparação do Médico 
Generalista/1986 (ABEM/MEC/F.

Kellogg), quando foi proposta a formação de "um médico capaz de diagnosticar e

resolver os problemas

de saúde mais

freqüentes em sua área

de atuação..."

Preocupação similar aparece nos

movimentos mundiais

de preparação para a

Conferência Mundial de

Educação Médica, de

1988 em Edimburgh,

promovida pela

Federação Mundial de

Educação Médica

(Feuerwerker, 1997, p.60-2). aliada à insatisfação dos usuários com os serviços recebidos.

Num contexto dessa natureza, como pensar a formação dos profissionais de saúde? E em que medida pode-se pensar uma intervenção no sistema de saúde via processo de formação?

\section{Aprendizado e realidade}

Pretender uma formação de profissionais socialmente contextualizada, que os instrumentalize para enfrentar os problemas de saúde da população, remete, não apenas ao perfil do profissional, ao conteúdo do ensino, às metodologias pedagógicas, mas também aos cenários pertinentes à formação - sua articulação com o mundo da prática, com a realidade social $e$ com as necessidades de saúde da população.

Considerando que é no cotidiano vivencial onde se ritualizam, problematizam, produzem e legitimam as formas do viver, o cotidiano é um ponto de referência por excelência para o direcionamento das práticas de ensino e práticas de investigação, enquanto práticas sociais que buscam contribuir para a melhoria da qualidade de vida das pessoas.

Seria, então, necessário reconhecer e incorporar, nas práticas pedagógicas, o cotidiano, uma vez que, a partir dele, pode-se visualizar um possível caminho para uma formação e prática profissional que leve em consideração o presente e os determinantes dos fenômenos saúde-doença; mesmo porque, "para poder estudar o processo saúde/enfermidade se requer considerar os sujeitos sãos e enfermos não unicamente para explicá-los e sim para compreendê-los e conjuntamente construir potencialidades de ação" (Granda apud Paim, 1998, p.310).

As intervenções sobre os problemas de saúde exigem ações que devem se orientar para a aplicação de conhecimentos muito além do hoje considerado técnico - científico; envolvem dimensões no campo das relações interpessoais $e$ institucionais, conflitos de valores e princípios. Mesmo problemas aparentemente de natureza técnica podem expressar conflitos latentes nos modos de pensar e atuar dos profissionais. De todo modo, não há aprendizagem adequada se os atores não tomam consciência do problema $e$ se nele não se reconhecem, em sua singularidade.

Segundo Paim (1996), para formar profissionais de saúde que atuem como sujeitos sociais comprometidos com a eqüidade, democracia $e$ emancipação humana, cuja prática permita uma mediação estratégica quanto às políticas mais amplas e à adoção de valores solidários à vida, algumas características devem ser enfatizadas, dentre elas: capacidade de análise do contexto em relação às práticas que realiza; compreensão da organização e gestão do processo de trabalho em saúde; exercício de um agir comunicativo ao lado do estratégico; atenção a problemas e necessidades de saúde; senso crítico quanto a efetividade e ética das intervenções propostas ou realizadas; permanente questionamento sobre o significado e sentido de seu trabalho e dos seus projetos de vida. 
Ou seja,

não somente se necessitam de conhecimentos para apreender a realidade, mas também se deve realizar uma aproximação gnoseológica distinta com vistas a encontrar na realidade - ademais de conhecimentos - saberes, desejos, sentidos, projeções de luta e mudança, que constituem também, aspectos fundamentais da ação humana. (Escuela de Salud Publica apud Paim, 1998, p.310)

Portanto, além de desenhos curriculares mais flexíveis, metodologias pedagógicas ativas, é de fundamental importância considerar os cenários de ensino-aprendizagem, dadas as possibilidades que oferecem ao processo $e$ a influência que exercem na formação de profissionais.

\section{Violência: problema prioritário de saúde}

A elevação da mortalidade por causas externas, no país e no mundo, sobretudo nos grandes centros urbanos, tem colocado a violência na pauta dos problemas nacionais e internacionais (Laurenti et al., 1972; Mello Jorge, 1979, 1981, 1982; Radis, 1984, 1985, 1990; World Bank, 1989; CBIA/ Unicef, 1991).

A inclusão da violência no campo da saúde, como está colocada na revisão sintética do relatório "Rastro da Violência em Salvador" (FCCV, 1998), ${ }^{4}$ se deu pela sua magnitude e transcendência expressa no caráter endêmico $e$ epidêmico que adquire em algumas áreas, pelo clima de medo e insegurança social $^{5}$ gerado pela veiculação na mídia das violências intencionais, pela tendência dos indivíduos recorrerem à violência como recurso para resolver problemas $^{6}$, bem como pelos altos custos para o setor saúde, decorrentes do atendimento às vítimas da violência.

A "Declaração da Conferência Interamericana sobre Sociedade, Violência $e$ Saúde", realizada pela Organização Panamericana da Saúde, em 1994, além de assumir a violência como problema de saúde, atribui, como gênese desse problema, as desigualdades e as injustiças sociais, as discriminações sociais, as quais destróem a democracia e o bem estar coletivo, geram frustrações,

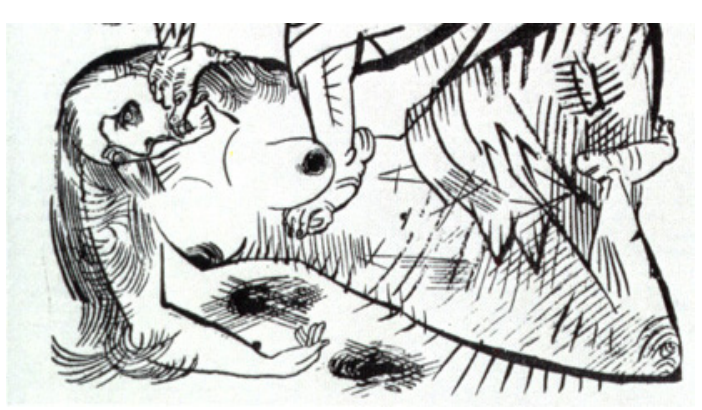

\author{
${ }^{4}$ Violência entendida \\ como ação intencional \\ realizada por \\ indivíduo ou grupo, \\ dirigida a outro que \\ resulte em óbito, \\ danos físicos, \\ psicológicos e / ou \\ sociais, implicando na \\ utilização da força \\ física ou da coação \\ psíquica e moral \\ (Franco, 1990)
}

${ }_{5}^{5}$ Pesquisa realizada em Salvador (Machado et al., 1997, p.202), revela que $89 \%$ dos entrevistados sente insegurança quando caminha nas ruas, $69 \%$, quando dirige seus carros e $52 \%$, nos locais de trabalho.

\footnotetext{
${ }^{6} \mathrm{O}$ "Projeto Atitudes e Normas Culturais frente à Violência em Cidades Selecionadas da Região das Américas" ACTIVA, (OPAS/UFBA/UNEB, 1997) - constatou que $5,6 \%$ dos entrevistados (equivalendo a 139.850 pessoas) possuíam arma de fogo e $21,1 \%$ pretendiam adquirir este instrumento. Encontraram, ainda, um contingente de $32 \%$ dos entrevistados que declararam estar dispostos a fazer justiça com as próprias mãos.
} 
marginalizam as populações, perpetuam os conflitos e lesam a integridade familiar. Ressalta, também, que é dever do Estado empreender todos os esforços necessários para reduzir os fatores que determinam a violência $e$ comprometem a qualidade de vida das pessoas, para assegurar a plena vigência do Estado de Direito. Além disso, convoca os governos de todos os países para assumirem como prioridade o desenvolvimento de planos $e$ programas intersetoriais de prevenção e controle da violência, bem como a promoção da convivência pacífica.

No Brasil, o trabalho de Souza \& Minayo (1995) registra que a violência representou para o país, ao longo dos anos 80 , a perda de 850.307 pessoas (número bem maior do que o resultante de alguns conflitos bélicos), na grande maioria mortas precocemente, em plena idade produtiva.

Assim, a mortalidade por causas externas tem assumido uma importância crescente no perfil epidemiológico da população brasileira, ocupando o segundo lugar nas principais capitais do país - Recife, São Paulo, Rio de Janeiro e Salvador - superadas apenas pelas doenças cardiovasculares. Contudo, ao se considerar a faixa etária de 15 a 49 anos, as diversas formas de violência assumem o primeiro lugar.

$E$, no conjunto das violências, os homicídios apresentam tendência de crescimento. Cabe salientar que os homicídios se acentuam principalmente entre as pessoas do sexo masculino e jovens. Sua participação entre as mortes por causas externas de crianças e adolescentes até 17 anos na Região Metropolitana de Salvador passou de 14,9\% em 1989, para 25,8\% em 1990 (Cedec, 1997), atingindo, em Salvador, 34,6\%, em 1997 (FCCV, 1997).

Em 1997, 1.578 residentes da cidade de Salvador sofreram mortes violentas, dentre os 4.123 laudos registrados no Instituto Médico Legal Nina Rodrigues. Entre as mortes violentas, $50,0 \%$ foram caracterizadas como homicídios, sendo a maioria das vítimas homens $(84,1 \%)$, jovens ( $46 \%$ entre 15 e 29 anos), negros (88,7\% entre negros e "pardos"), solteiros, desempregados ou subempregados. A arma de fogo foi responsável em Salvador, por 80,9\% dos óbitos por homícidio, revelando o problema do tráfico de armas nesta região.

Estes números, baseados no registro de mortes, não expressam todo o espectro do problema.

A violência praticada contra a mulher, por exemplo, assume outras características - em função da maneira como esta é socializada - e nem sempre se torna visível, a exemplo da violência doméstica, que ocorre no âmbito das relações particulares entre integrantes da mesma família, tendo normalmente a casa como o espaço físico privilegiado para sua manifestação. Segundo dados divulgados pelo IBGE em 1990, a ocorrência da violência física contra mulheres é quase três vezes maior do que contra os homens (32\% para 10\%), e $63 \%$ das agressões físicas contra mulheres acontecem na sua própria residência". (FCCV, p. 16, 1998)

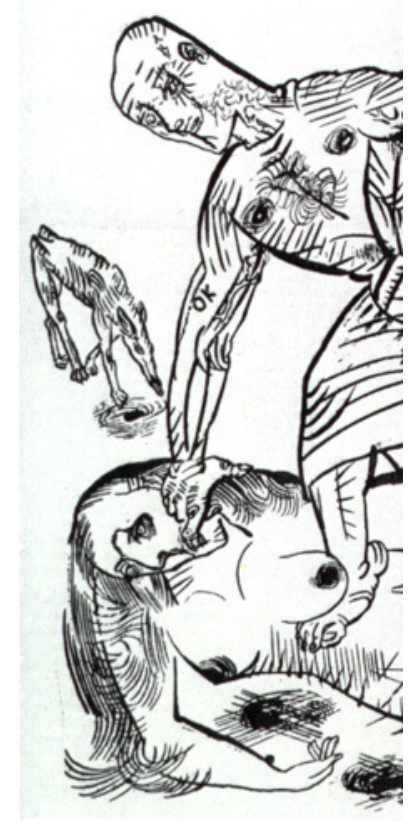


O relatório "Rastro da Violência em Salvador" (FCCV, 1998), baseado nos registros de 1997 do Instituto Médico Legal Nina Rodrigues, demonstra ainda que as classes menos favorecidas são freqüentemente mais vítimas da violência urbana. Ou seja, esses eventos não atingem de forma igualitária todos os segmentos da população. Reforça-se, portanto, a compreensão de que em uma sociedade marcadamente desigual no que se refere aos direitos sociais do cidadão, a mortalidade e a morbidade também se apresentam de modo desigual, tornando algumas camadas da população mais vulneráveis do que outras.

Se não há como deixar de considerar a violência como parte da realidade da vida e da saúde das populações, então é preciso enfrentar a necessidade de preparar profissionais de saúde para atuar na prevenção, diagnóstico, tratamento, cuidado e reabilitação das condições complexas de saúde. Para que se possa produzir impacto sobre elas, precisa-se de intervenções que ultrapassem o âmbito já delimitado do setor de saúde.

\section{O ensino-aprendizagem e a violência}

\section{a perspectiva da construção de novas práticas sanitárias}

Os Projetos $\mathrm{UNI}^{7}$ têm assumido o desafio de formar profissionais de saúde preparados para resolver os problemas de saúde da maioria da população, experimentar modelos de atenção mais eqüitativos $e$ eficazes e desenvolver a participação social em saúde. Tal desafio exigiu um deslocamento do eixo da formação, centrado no hospital $e$ na atenção curativa, para uma formação que instrumentalizasse $o$ aluno para atender as necessidades sociais de saúde. Exige pensar a formação de profissionais para uma assistência à saúde baseada no princípio da integralidade da atenção.

Nesse sentido, uma primeira questão está posta: como simultaneamente provocar mudanças nos modelos de ensino e de atenção, uma vez que os cenários existentes, o mundo da prática, retratam um modelo a ser superado?

Para fazer frente a esta situação, o UNI - Bahia assume, como eixo para o trabalho em parceria (universidade, serviços de saúde e comunidade), o enfrentamento dos problemas de saúde definidos como prioritários na sua área de atuação. Os problemas de saúde se constituíram no foco de convergência dos interesses dos parceiros e no espaço que dá o sentido para a existência e articulação das ações do conjunto dos atores envolvidos em direção a objetivos acordados. Ou seja, considera-se que os problemas de saúde têm potencial para mobilizar vontades, agregando diferentes interesses da academia, dos serviços e da comunidade; e são, também potencialmente, capazes de dar direcionalidade às ações, tornando-as socialmente relevantes.

\footnotetext{
${ }^{7}$ Os Projetos UNI - Uma Nova Iniciativa na Educação dos profissionais de saúde: união com a comunidade, iniciativa da Fundação Kellogg, desenvolvida a partir de 1992, foram implantados em 23 universidades de 11 países da América Latina, tem como principal estratégia o estabelecimento de parceria entre ensino, serviço de saúde e comunidade, com propósito de desencadear mudanças no modelo de ensino e de atenção à saúde, bem como na forma de participação social em saúde (Kisil \& Chaves, 1994).
} 


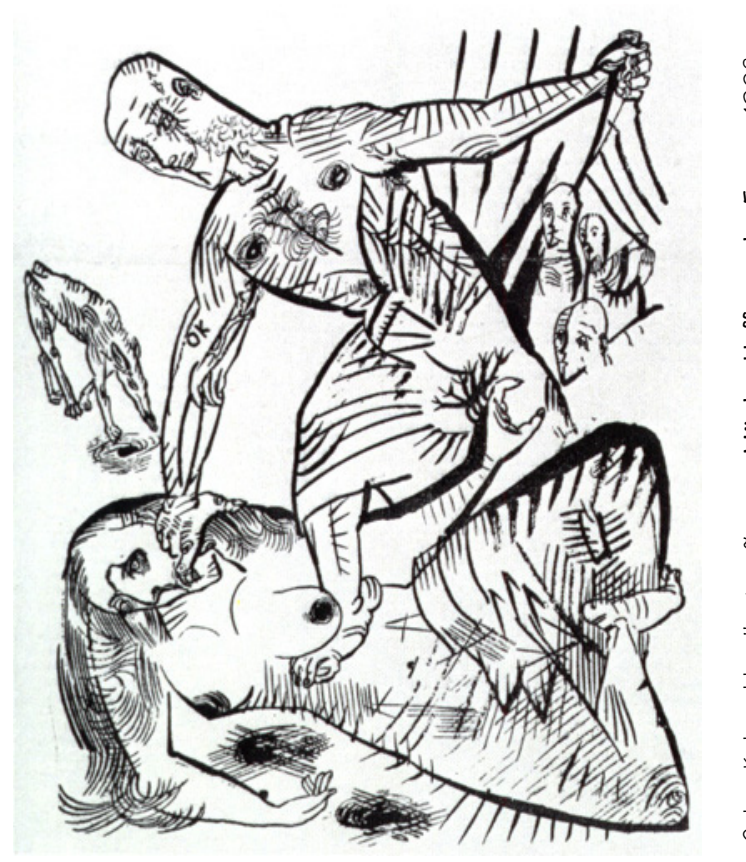

Na perspectiva da reorganização da atenção à saúde, ao trabalhar tendo os problemas como eixo, pretende-se um deslocamento do objeto de intervenção do setor saúde, que passa a ter outras conformações para além do indivíduo doente, $e$ força a utilizacão de outros meios de trabalho e de outras articulações que transcendem o âmbito do setor de saúde. Além disso, traz a possibilidade de conformar práticas articuladas de promoção, proteção, recuperação e reabilitação da saúde, com todo o espectro de conhecimento e técnica que são próprios do setor.

A partir dessa opção, no âmbito do Projeto UNI-BAHIA, comunidade, profissionais de saúde, alunos e professores da universidade identificaram e definiram os problemas prioritários - e a violência desponta como o principal agravo da área. No mesmo período é publicado o relatório sobre a Análise da Situação de Saúde no Município de Salvador (Paim, 1995), apontando a violência como segunda causa de morte da população $e$ primeira causa, se considerada a faixa etária de menores de 49 anos.

Definir a violência como problema prioritário da área do Distrito Sanitário Barra/Rio Vermelho (área de atuação do UNI - Bahia) veio reforçar a perspectiva apontada pelo Projeto, na medida em que o enfrentamento desse problema tem exigido um conhecimento interdisciplinar, uma prática multiprofissional e uma articulação intersetorial. Tem possibilitado, portanto, um espaço de ensino-aprendizagem prático, no qual está sendo possível a atuação articulada de alunos, professores, comunidade e pessoal de serviços de saúde.

Sendo um problema não tratado usualmente pelo setor saúde, exceto no que se refere à assistência médico-hospitalar, a violência tem forçado a busca de alternativas de ação que estão fora dos mecanismos e das possibilidades usuais desse setor. A necessidade de encontrar meios que possam impactar, com mais efetividade, o problema, tem levado à intersetorialidade, à articulação de conhecimentos e de instrumentos de distintas áreas do saber, à articulação ensino/pesquisa/ação-intervenção. 


\section{O Fórum Comunitário de Combate à Violência}

\section{a articulação universidade/comunidade/serviços}

A constatação feita por representantes da comunidade, profissionais de serviços, professores e alunos da disciplina Políticas de Saúde, do aumento na violência em áreas de atuação do UNI-Ba., situação confirmada pelo relatório da pesquisa "Análise da Situação de Saúde no município de Salvador" (Paim, 1995), motivou a realização, em 1996, na comunidade do Vale das Pedrinhas, do Seminário sobre Violência e Saúde. Desse evento saiu a proposição de constituição de um fórum que agregasse os diversos setores interessados e envolvidos com a questão da violência, para coordenar as ações de enfrentamento desse problema.

Assim, em agosto de 1996, o Fórum Comunitário de Combate à Violência foi constituído pelos segmentos do Projeto UNI-BAHIA, para operacionalizar as práticas intersetoriais inerentes ao enfrentamento desse complexo $e$ multifacetado problema de saúde. Nessa perspectiva, incluiu em sua organização outros setores governamentais e não governamentais das áreas de educação, segurança pública, do setor jurídico e social, passando a ser o organismo coordenador das ações contra a violência na área de atuação do Projeto, o Distrito Sanitário Barra Rio Vermelho.

A partir da constituição do Fórum, todos os seus componentes, incluindo profissionais de saúde, segurança pública, representantes das organizações comunitárias, professores e alunos das

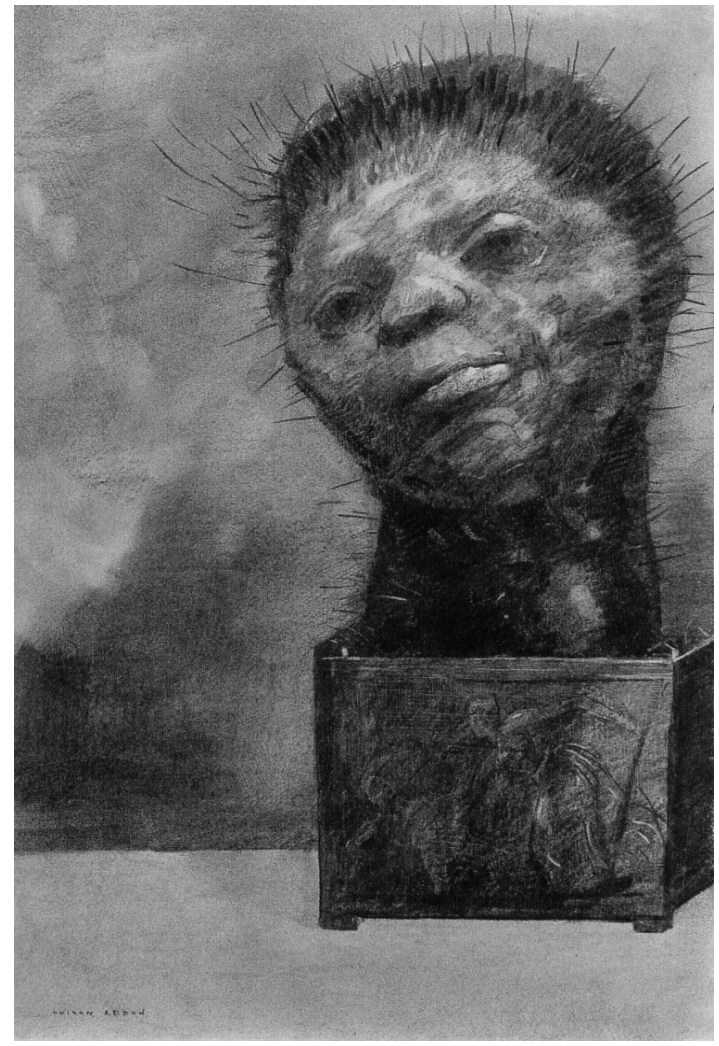
diversas áreas, participaram da elaboração do plano de ação para o combate à violência, o qual tem orientado as práticas dos diversos setores e segmentos em quatro linhas de ação: monitoramento e produção de conhecimento sobre a violência; organização de uma rede de atendimentos às vítimas da violência, programa educativo junto a escolares; $e$ mobilização social. Assim, desde a fase inicial de operacionalização do Plano Operativo de Combate à Violência até o presente momento (quatro semestres letivos) a atuação dos alunos, dos profissionais de saúde e da comunidade tem sido marcante no desenvolvimento das linhas de ação definidas pelo Fórum.

$\mathrm{O}$ quadro a seguir ilustra as atividades em desenvolvimento:

ODILE REDON, O homem cactus, 1882.

Coleção lan Woodner, Nova lorque 
A PROBLEMATIZAÇÃO DA VIOLÊNCIA...

\begin{tabular}{|c|c|c|c|}
\hline PROJETO & LINHAS DE AÇ ÃO & INTEGRANTES & RESULTADOS \\
\hline $\begin{array}{l}\text { SISTEMA DE } \\
\text { VIGILÂNCIA DAS } \\
\text { VIOLÊNCIAS }\end{array}$ & \multirow{2}{*}{$\begin{array}{l}\text { Monitoramento e } \\
\text { produção de } \\
\text { conhecimento } \\
\text { sobre a violência; }\end{array}$} & $\begin{array}{l}\text { Professores, alunos de medicina da disciplina } \\
\text { de Políticas de Saúde - Instituto de Saúde } \\
\text { Coletiva; profissionais do Instituto de } \\
\text { Medicina Legal Nina Rodrigues e profissionais } \\
\text { da gerência e da rede de serviços do Distrito } \\
\text { Sanitário/técnicos contratados pela Unicef. }\end{array}$ & \multirow{2}{*}{$\begin{array}{c}\text { Relatório "Rastro } \\
\text { da Violência em } \\
\text { Salvador"; } \\
\text { pesquisas (entre } \\
\text { elas "Violência entre } \\
\text { escolares"); } \\
\text { projeto para o } \\
\text { monitoramento da } \\
\text { morbidade da } \\
\text { violência; }\end{array}$} \\
\hline $\begin{array}{l}\text { SISTEMA DE } \\
\text { VIGILÂNCIA } \\
\text { EPIDEMIOLÓGICA } \\
\text { DOS HOMICÍDIOS }\end{array}$ & & $\begin{array}{c}\text { Professores, alunos de medicina da disciplina } \\
\text { de Políticas de Saúde - Instituto de Saúde } \\
\text { Coletiva; profissionais da gerência e da rede } \\
\text { de serviços do Distrito Sanitário; técnicos do } \\
\text { nível central das Secretarias Estadual e } \\
\text { Municipal de Saúde }\end{array}$ & \\
\hline $\begin{array}{l}\text { ESTRUTURAÇÃO DA } \\
\text { REDE DE } \\
\text { ATENDIMENTO ÀS } \\
\text { VÍTIMAS DA } \\
\text { VIOLÊNCIA }\end{array}$ & $\begin{array}{l}\text { Organização de } \\
\text { uma rede de } \\
\text { atendimento às } \\
\text { vítimas da } \\
\text { violência }\end{array}$ & $\begin{array}{c}\text { Professores, alunos de medicina da disciplina } \\
\text { Políticas de Saúde, curso de Medicina/ISC; } \\
\text { profissionais da rede (unidades de saúde, } \\
\text { órgãos de segurança pública, ministério } \\
\text { público e ONG's) }\end{array}$ & $\begin{array}{c}\text { Guia de Serviços } \\
\text { para informar à } \\
\text { população e aos } \\
\text { profissionais } \\
\text { envolvidos sobre os } \\
\text { serviços } \\
\text { existentes }\end{array}$ \\
\hline $\begin{array}{l}\text { PROGRAMA } \\
\text { CIDADANIA PARA A } \\
\text { PAZ }\end{array}$ & \multirow{2}{*}{$\begin{array}{l}\text { Desenvolvimento } \\
\text { de programa } \\
\text { educativo junto a } \\
\text { escolares }\end{array}$} & $\begin{array}{l}\text { Alunos da disciplina Desenvolvimento da } \\
\text { Comunidade e Comunicação, curso de } \\
\text { Nutrição; representantes da comunidade }\end{array}$ & \multirow{2}{*}{$\begin{array}{c}\text { Trabalhos } \\
\text { educativos com } \\
\text { escolares, alunos e } \\
\text { professores } \\
\text { (Enfermagem, } \\
\text { Nutrição e } \\
\text { Psicologia) } e \\
\text { professores da } \\
\text { rede de ensino }\end{array}$} \\
\hline $\begin{array}{c}\text { PROGRAMA } \\
\text { COMBATE À } \\
\text { VIOLÊNCIA NAS } \\
\text { ESCOLAS DE ENSINO } \\
\text { MÉDIOE } \\
\text { FUNDAMENTAL NO } \\
\text { DISTRITO SANITÁRIO } \\
\text { BARRA/RIO } \\
\text { VERMELHO }\end{array}$ & & $\begin{array}{c}\text { Alunos da disciplina Desenvolvimento da } \\
\text { Comunidade e Comunicação, curso de } \\
\text { Nutrição; representantes da comunidade e } \\
\text { professores das escolas }\end{array}$ & \\
\hline $\begin{array}{l}\text { TREINAMENTO DE } \\
\text { ADOLESCENTES }\end{array}$ & $\begin{array}{l}\text { Mobilização social } \\
\text { para desenvolver } \\
\text { cidadania e auto- } \\
\text { estima }\end{array}$ & $\begin{array}{c}\text { Alunos da disciplina Odontologia Social, curso } \\
\text { de Odontologia; alunos da disciplina } \\
\text { Introdução à Medicina Social, curso de } \\
\text { Medicina; profissionais dos serviços de saúde; } \\
\text { grupos de adolescentes da comunidade e } \\
\text { representantes da associação de moradores } \\
\text { da área }\end{array}$ & $\begin{array}{l}\text { Formação de } \\
\text { agentes } \\
\text { multiplicadores } \\
\text { para a saúde }\end{array}$ \\
\hline $\begin{array}{l}\text { DECLARE AMOR } \\
\text { AO SEU BAIRRO }\end{array}$ & $\begin{array}{l}\text { campanhas } \\
\text { publicitárias }\end{array}$ & $\begin{array}{l}\text { alunos e professores de Medicina, } \\
\text { Enfermagem, Nutrição, Medicina Veterinária, } \\
\text { Psicologia e Farmácia, profissionais dos } \\
\text { serviços, representantes da Polícia Militar e } \\
\text { de delegacias especializadas, alunos de } \\
\text { outras áreas e lideranças comunitárias }\end{array}$ & $\begin{array}{l}\text { organização e } \\
\text { realização de feiras } \\
\text { de Saúde e outros } \\
\text { eventos }\end{array}$ \\
\hline
\end{tabular}


Além dos resultados para o ensino, o trabalho tem estimulado a mudança de práticas de organizações e instituições parceiras: a Delegacia de Proteção à Mulher tem estruturado o seu trabalho para desenvolver ações preventivas, pelo acompanhamento psicológico e social de famílias consideradas de risco. Além disso, organizou um sistema de informação que permite o mapeamento constante de ocorrência de atos violentos para identificar as áreas e situações de risco, a fim de garantir uma atuação mais oportuna e imediata. A Polícia Militar está implantando o projeto "Polícia Comunitária", em articulação com a comunidade, que busca, ao lado da repressão não violenta ao crime, participar de medidas de prevenção da violência, aliada a uma atuação de proteção ao cidadão.

As ações do Fórum têm extrapolado seu âmbito de atuação, indo além de atividades no espaço do Distrito Sanitário Barra Rio Vermelho. A Secretaria Estadual de Saúde deu um destaque à questão da violência quando elaborou, como desdobramento do Plano Estadual de Saúde, o Plano de Ação para a Redução da Morbimortalidade por Causas Externas na Bahia - PARMCEX, designando o Departamento de Vigilância à Saúde para coordenar e implementar as ações de combate à violência. Esse Departamento está trabalhando em articulação com o Fórum, compondo, inclusive sua Secretaria Executiva. Vale registrar que o PARMCEX foi aprovado, por unanimidade e com voto de louvor, pelo Conselho Estadual de Saúde, em setembro de 1998.

Na Universidade, o projeto UFBA em Campo, iniciativa da Pró-Reitoria de Extensão, visando promover o desenvolvimento de práticas dos alunos das diversas carreiras, pela articulação entre ensino, serviços e sociedade, organizou, em 1998, a participação da Universidade no Carnaval, através do Projeto Folia Universitária, com o propósito de estimular um carnaval sem violência. Seu objetivo acadêmico foi, também, o de realizar atividades de pesquisa sobre o carnaval (visando produzir conhecimento sobre a produção do carnaval no seu lado "oculto"). O Folia Universitária, juntamente com o Fórum e o Diretório Central dos Estudantes, organizou e participou da "Caminhada pela Paz", abrindo o carnaval, numa das áreas mais concorridas de Salvador.

Segmentos religiosos e organizações que lidam com questões relacionadas aos Direitos Humanos têm buscado articular-se ao Fórum e estão desenvolvendo campanhas em favor da paz e pela não violência. Os canais de TV, os jornais e as rádios locais têm mantido reportagens freqüentes sobre a violência e divulgado o trabalho do Fórum. Em 1998, empresas ligadas à propaganda e publicidade engajaram-se no trabalho do Fórum e elaboraram uma campanha, com produção de outdoors, cartazes, folhetos, adesivos, spots para rádio e clips para televisão.

\section{Considerações finais}

Mesmo no espaço singular de algumas disciplinas, a experiência vem demonstrando que o ensino centrado no aluno e pautado nos problemas $e$ necessidades de saúde da população tem contribuído para uma atuação multiprofissional e intersetorial, permitindo o desenvolvimento de ações nos diversos níveis de atenção, que buscam enfrentar os problemas, beneficiando os indivíduos e a comunidade.

Esse cenário tem garantido um espaço de atuação que permite planejamento, elaboração de projetos, realização de pesquisas, manejo de 
sistemas de informação, organização de serviços, assistência e comunicação social em saúde (interação com diferentes grupos da comunidade, com outros profissionais e com distintas organizações). Enfim, tem permitido uma inserção no mundo do trabalho, na realidade, resultando em intervenções que possibilitam a experimentação de novos instrumentos de trabalho e de novas formas de agir em saúde.

As articulações, tanto com diferentes profissionais, como com diferentes setores, exigem, também, o desenvolvimento da capacidade de negociação, bem como habilidade para lidar com o outro - portador de distintos interesses $e$ distintos saberes. Um verdadeiro estímulo à capacidade relacional -

intervenções que não se reduzem a aplicação de um instrumental técnico e/ou de um conhecimento dado à priori.

$O$ processo de avaliação $e$ auto-avaliação discente tem apontado esse espaço como privilegiado para o desenvolvimento de habilidades $e$ atitudes que instrumentalizam os alunos para entenderem e enfrentarem a realidade concreta, compreendendo o significado e a dimensão da Saúde Coletiva e o compromisso social da universidade. Além de contribuir para o amadurecimento pessoal.

Estamos constatando que os resultados até então alcançados se aproximam, em muito, dos propósitos e princípios que orientaram a experiência e que em muito se aproximam daqueles contidos nas propostas de Diretrizes Curriculares apresentadas pela Rede UNIDA ao Ministério da Educação, fruto de um amplo debate entre os projetos que lidam com a formação de recursos humanos para a saúde, dentre eles:

currículos fundamentados no humanismo e em metodologias ativas; relação de equilíbrio entre teoria e prática; diversificação dos cenários de aprendizagem; pesquisa integrada ao ensino, com participação de profissionais dos serviços e da comunidade; educação orientada aos problemas mais relevantes da comunidade; educação centrada no aluno visto como sujeito do processo de ensino-aprendizagem. (REDE UNIDA, 1998, p.12)

\section{Referências bibliográficas}

CENTRO BRASILEIRO PARA A INFÂNCIA E ADOLESCÊNCIA - CBIA./UNICEF. Bahia, suas crianças e adolescentes: o que está acontecendo? Salvador, 1991, p. 99-121.

CENTRO DE ESTUDOS DE CULTURA CONTEMPORÂNEA -CEDEC. Mapa de risco da violência: cidade de Salvador. São Paulo, 1997. p.2-5.

FEUERWERKER, L. C. M. Mudanças na educação médica e residência médica no Brasil. São Paulo, 1997. 230p. Dissertação (Mestrado) Faculdade de Saúde Pública, Universidade de São Paulo.

FÓRUM COMUNITÁRIO DE COMBATE À VIOLÊNCIA -FCCV/PROJETO UNI BA./UFBA/UNICEF. Rastro da violência em Salvador: mortes violentas de residentes em Salvador, 1997. Salvador, 1998. p.1-39.

FRANCO, S. La Violência: um problema de salud Publica que se agrava en la región. Bol. Epidemiol., v.11, n.2, p.1-7, 1990. 
KISIL, M., CHAVES, M. Programa UNI: uma nova iniciativa na educação dos profissionais de saúde. Battle Creek: Fundação W. K. Kellogg, 1994.

LAURENTI, R. et al. Alguns aspectos epidemiológicos da mortalidade por acidentes de trânsito de veículo a motor na Cidade de São Paulo, Brasil. Rev. Saúde Pública, v.6, p.329-41, 1972.

MACHADO, E., NORONHA, C., CARDOSO, F. No olho do furacão - brutalidade policial, preconceito racial e controle da violência em Salvador. Rev. Afro-Ásia Centr. Estud. Afro-Orientais., v.19/20, p.201-26, 1997.

MELLO JORGE, M.H.P. Mortalidade por causas violentas no município de São Paulo. São Paulo, 1979. 281p. Tese (Doutorado), Faculdade de Saúde Pública, Universidade de São Paulo.

MELLO JORGE, M.H.P. Mortalidade por causas violentas no município de São Paulo, Brasil III - Mortes intencionais. Rev. Saúde Pública, v.15, p. 1655-93, 1981.

MELLO JORGE, M.H.P. Mortalidade por causas violentas no município de São Paulo, Brasil IV - A situação em 1980. Rev. Saúde Pública, v.16, p. 19-41, 1982.

OPAS/UFBA/UNEB. Projeto ACTIVA - Região Metropolitana de Salvador. Salvador, 1997.

OPS. Declaração da Conferência Interamericana sobre Sociedade, Violência $e$ Saúde (aprovada por aclamação em Washington D.C., 17 de novembro de 1994) Bol. ABRASCO, v.13, n.2, p.65-6, 1995.

PAIM, J. S. (Coord.) Análise da situação de saúde no município de Salvador: segundo condições de vida. Salvador: UFBA/SMS/CNPq/OPAS, 1995.

PAIM, J. S. (Coord.) O ensino das profissões de saúde: entrevista. Rede Ida Brasil, 1996. (Encarte, 19).

PAIM, J. S., ALMEIDA, N. Saúde coletiva: nova saúde pública ou campo aberto a novos paradigmas? Rev. Saúde Pública, v.32, p.299-316, 1998.

PEREIRA, M. L. T. Notas sobre Educação na transição para um novo paradigma. Interface - Comun., Saúde, Educ., v.1, n.1, p. 51-68, 1997.

REDE UNIDA. Contribuição para as novas diretrizes curriculares dos cursos de graduação da área da saúde. Olho Mágico, v.4, n.16, 1998.

SOUZA, E. R., MINAYO, M. C. O impacto da violência social na Saúde Pública do Brasil: década de 80. In: MINAYO, M. C. (Org.). Os muitos brasis: saúde e população na década de 80. São Paulo: HUCITEC, 1995. p.87-116.

WORLD BANK. Population and Human Resources Division Brazil Country Department Health Policy in Brazil: adjusting to new challenges. Washington, 1989. Chapt. III-2, III-3, III-4.

COSTA, H. O. G. La problemática de la violencia como experiencia de enseñar en Salud, Interface _ Comunicação, Saúde, Educação, v.3 , n.5, 1999.

El artículo relata el afrontamiento de la violencia como problema prioritario de salud de la población del área de actución del proyecto Uni-Bahia - Distrito Sanitário Barra/Rio Vermelho, Brasil. Discute la necesidad de una formación socialmente contextuada que ayude a los profesionales a afrontar los problemas y las necesidades reales de salud de la población. Comenta las estrategias utilizadas para asegurar una articulación estrecha entre el mundo de la enseñanza y el mundo del trabajo - la realidad.

PALABRAS-CLAVE: violencia; proceso enseñanza-aprendizaje. 